\title{
Prevalence of acute and chronic viral seropositivity and characteristics of disease in patients with psoriatic arthritis treated with cyclosporine: a post hoc analysis from a sex point of view on the observational study of infectious events in psoriasis complicated by active psoriatic arthritis
}

\author{
This article was published in the following Dove Press journal: \\ Clinical, Cosmetic and Investigational Dermatology \\ 22 December 2015 \\ Number of times this article has been viewed
}

\section{Delia Colombo' \\ Sergio Chimenti² \\ Paolo Antonio Grossi ${ }^{3}$ \\ Antonio Marchesoni ${ }^{4}$ \\ Federico Bardazzi ${ }^{5}$ \\ Fabio Ayala ${ }^{6}$ \\ Lucia Simoni $^{7}$ \\ Donatella Vassellatti' \\ Gilberto Bellia' \\ On behalf of SYNERGY \\ Study Group \\ 'Novartis Farma Italia, Origgio (VA), \\ ${ }^{2}$ Tor Vergata Polyclinic Rome, ${ }^{3}$ Macchi Hospital and Foundation, Varese, \\ ${ }^{4}$ Orthopaedic Institute Pini, Milan, \\ ${ }^{5} S$ Orsola-Malpighi Polyclinic, Bologna, \\ 'University Federico II Naples, \\ 7 MediData srl, Modena, Italy}

Correspondence: Delia Colombo Novartis Farma Italia, Largo U Boccioni, I, 2 1040, Origgio, Varese, Italy Email delia.colombo@novartis.com
Background: Sex medicine studies have shown that there are sex differences with regard to disease characteristics in immune-mediated inflammatory diseases, including psoriasis, in immune response and susceptibility to viral infections. We performed a post hoc analysis of the Observational Study of infectious events in psoriasis complicated by active psoriatic arthritis (SYNERGY) study in patients with psoriatic arthritis (PsA) treated with immunosuppressive regimens including cyclosporine, in order to evaluate potential between-sex differences in severity of disease and prevalence of viral infections.

Methods: SYNERGY was an observational study conducted in 24 Italian dermatology clinics, which included 238 consecutively enrolled patients with PsA, under treatment with immunosuppressant regimens including cyclosporin A. In this post hoc analysis, patients' demographical data and clinical characteristics of psoriasis, severity and activity of PsA, prevalence of seropositivity for at least one viral infection, and treatments administered for PsA and infections were compared between sexes.

Results: A total of 225 patients were evaluated in this post hoc analysis, and 121 (54\%) were males. Demographic characteristics and concomitant diseases were comparable between sexes. Statistically significant sex differences were observed at baseline in Psoriasis Area and Severity Index score (higher in males), mean number of painful joints, Bath Ankylosing Spondylitis Disease Activity Index, and the global activity of disease assessed by patients (all higher in females). The percentage of patients with at least one seropositivity detected at baseline, indicative of concomitant or former viral infection, was significantly higher among women than among men. No between-sex differences were detected in other measures, at other time points, and in treatments. Patients developed no hepatitis $\mathrm{B}$ virus or hepatitis $\mathrm{C}$ virus reactivation during cyclosporine treatment.

Conclusion: Our post hoc sex analysis suggests that women with PsA have a greater articular involvement and a higher activity of disease compared to males. Immunosuppressive treatment with cyclosporine seems not to increase susceptibility to new infections or infectious reactivations, with no sex differences.

Keywords: psoriatic arthritis, sex, viral infections, SYNERGY, cyclosporine 


\section{Background}

Sex medicine aims to investigate how diseases differ between men and women in terms of prevalence, manifestation, severity, therapeutic approach, and prognosis. Sex differences with regard to disease characteristics and/or therapeutic approach have been reported in immune-mediated inflammatory diseases, including rheumatoid arthritis, inflammatory bowel diseases, and psoriasis. ${ }^{1,2}$ Marked sex differences have also been described in the susceptibility to viral infections, other than their incidence and manifestations. ${ }^{3-7}$ This observation may be linked to the fact that sex hormones seem to have significant effects on cell-mediated immune responses, as shown by several clinical and experimental studies. ${ }^{8-10}$

Psoriatic arthritis (PsA) is a disabling complication that occurs in 6\%-39\% of psoriatic patients, ${ }^{11}$ usually following skin manifestations and generally characterized by synovitis, enthesitis, dactylitis, and spondylitis. ${ }^{12}$ Patients with PsA are often treated with systemic immunosuppressant agents (eg, steroids, methotrexate, cyclosporin A [CsA]), which are known to increase the risk of new infections or of previous infection reactivation, though clinical data are scarce. Regarding anti tumor necrosis factor alpha, data suggest that therapy with these agents would appear efficacious and reasonably safe in the management of PsA patients with concomitant infections. ${ }^{13-17}$

The Observational Study of infectious events in psoriasis complicated by active psoriatic arthritis (SYNERGY) study is a cross-sectional and longitudinal (12 months) multicenter Italian study, involving 238 consecutive patients with diagnosis of PsA performed within 8 years from baseline, treated from at least 3 months with CsA as monotherapy or in combination with one or more systemic drugs. The SYNERGY study aimed at assessing: 1) seropositivity for former and acute viral infection; 2) effectiveness of CsA alone or in combination in a time period of 12 months; and 3) occurrence of infections or other adverse events during the study period. ${ }^{18}$ The results revealed a high prevalence of viral seropositivity - herpes simplex virus 1 (92.3\%), herpes simplex virus $2(67 \%)$, varicella-zoster virus $(95.3 \%)$, Epstein-Barr virus (89.2\%), cytomegalovirus (77.3\%), and hepatitis B virus $(6.1 \%)$ - but no viral reactivation during the 12-month observation period. However, sex differences in seropositivity were not analyzed. Since many differences between sexes have been reported in psoriatic patients, in terms of epidemiology, ${ }^{19}$ pattern and burden of disease, ${ }^{20}$ but also in immune response as well as susceptibility to viral infections, ${ }^{21}$ it was decided to perform a post hoc analysis to evaluate for potential differences between sexes in severity of disease, response to treatment, and prevalence of viral infections.

\section{Methods}

Ethical approval was obtained from the Ethical Committee of "G. Pini" Institute of Milan (principal center) and then from each participating center and signed informed consent was obtained from participating patients. SYNERGY was a crosssectional and longitudinal (12 months) observational study, conducted in 24 Italian dermatology clinics, which included 238 consecutively enrolled patients with PsA. Patients and methods of the study are described in detail elsewhere. ${ }^{18}$

Patients of the SYNERGY study were considered evaluable for this post hoc analysis, provided that sex was specified. According to the SYNERGY inclusion criteria, patients had:

- a diagnosis of psoriasis complicated by PsA, according to the ClASsification for Psoriatic ARthritis criteria ${ }^{22,23}$ performed within 8 years before baseline;

- an ongoing treatment with immunosuppressant regimens including CsA;

- no other form of arthritis besides PsA.

In this analysis, the following variables were compared between sexes at baseline and at 6 and 12 months of follow-up:

- age and demographical characteristics;

- age at diagnosis of psoriasis;

- duration of psoriasis;

- vaccinations administered;

- body surface area;

- Psoriasis Area and Severity Index (PASI);

- Bath Ankylosing Spondylitis Disease Activity Index (BASDAI);

- global activity of disease;

- number of painful and swollen joints;

- seropositivity for at least one infection;

- treatments for PsA (topical, infiltrations, systemic, ie, cyclosporine, methotrexate, biologics);

- pharmacological treatments for infections;

- adverse events.

The BASDAI is a useful composite measure in spondyloarthropathies and, when the SYNERGY study was designed, it was chosen hypothesizing that, since PsA has both peripheral and axial clinical manifestations, indices that measure only peripheral joint activity, such as the Disease Activity Score or the American College of Rheumatology response criteria, may not capture sufficient information to truly reflect disease activity in PsA. 
Indexes of disease severity and activity were also compared between premenopausal and postmenopausal women and men of corresponding age, taking as cut off 50 years, since in Italy, the average age for last period is $\sim 50$ years. ${ }^{24}$

All analyses were performed with SAS version 9.2 (SAS Institute Inc., Cary, NC, USA) and Enterprise Guide 4.3 (SAS Institute Inc., Cary, NC, USA). Descriptive analyses were mean and standard deviation (SD), or median and interquartile range. Comparisons were performed by Student's $t$-test, chi-square test, or Fisher's exact test, if appropriate. The accepted level of significance was set at alpha $=0.05$. As post hoc analyses, all $P$-value presented are exploratory.

\section{Results}

In the SYNERGY study, 238 patients were enrolled, but 13 patients not fulfilling the inclusion criteria were excluded from the analysis. ${ }^{18}$ Therefore, 225 patients were evaluated in this post hoc analysis, of which 121 (54\%) were males. The distribution of patients according to sex, age, and concomitant diseases at baseline is shown in Table 1; no statistically significant differences were observed between males and females with respect to these variables ( $P$-values males vs females $>0.05)$ as well as in the vaccination profile $(2.5 \%$ of males and $6.7 \%$ of females were vaccinated at baseline; Fisher's exact test, $P$-value $=0.2045$ ).

Table I Age, concomitant diseases, and viral status of the SYNERGY male and female patients at baseline

\begin{tabular}{llll}
\hline & $\begin{array}{l}\text { Males } \\
(\mathbf{N}=12 \text { I) }\end{array}$ & $\begin{array}{l}\text { Females } \\
\mathbf{( N = 1 0 4 )}\end{array}$ & P-value \\
\hline Age, mean (SD) & $48.9($ I2.8) & $50.8(12.5)$ & 0.2499 \\
Concomitant diseases (\%) & 45.5 & 48.1 & 0.6942 \\
Cardiovascular diseases & 24.8 & 30.8 & \\
Type I diabetes & 3.3 & 0 & \\
Type 2 diabetes & 7.4 & 3.8 & \\
Cerebrovascular diseases & 0 & 1 & \\
Renal diseases & 2.5 & 1.9 & \\
Other diseases & 21.5 & 21.2 & \\
Viral positivity (\%) & 53.7 & 68.3 & \\
HBV & 5 & 3.8 & \\
HCV & 5.8 & 3.8 & \\
Cytomegalovirus & 36.4 & 46.2 & \\
HIV I-2 & 0 & 0 & \\
HSV I & 42.1 & 53.8 & \\
HSV 2 & 31.4 & 37.5 & \\
Varicella-zoster virus & 17.4 & 19.2 & \\
Epstein-Barr virus & 32.2 & 42.3 & \\
\hline
\end{tabular}

Abbreviations: HBV, hepatitis B virus; HCV, hepatitis C virus; HIV, human immunodeficiency virus; HSV, herpes simplex virus; SD, standard deviation; SYNERGY, Observational Study of infectious events in psoriasis complicated by active psoriatic arthritis.
Regarding the severity of psoriasis, PASI score at baseline was significantly higher in males compared with females (8.0 [SD 7.7] in males vs 5.8 [SD 6.9] in females; $t$-test, $P$-value $=0.028$ ). As shown in Figure 1 , in terms of severity of PsA at baseline, differences between sexes emerged in the mean number of painful (but not of swollen) joints and in the global activity of disease, as assessed by patients (but not by physicians). Consistently, also the BASDAI at baseline was higher in females (44.9 [SD 22.9]) than in males (36.5 [SD 22.8]; $t$-test, $P$-value $=0.036$ ). Severity of both psoriasis and PsA progressively diminished at 6 and 12 months of follow-up, as did differences between sexes, which were no longer significant after baseline except for painful joint count at 6-month follow-up (4.6 [SD 7.5] in males vs 8.0 [SD 10.1] in females; $t$-test, $P$-value $=0.0162$ ) and swollen joint count at 12-month follow-up (0.7 [SD 1.4] in males vs 1.6 [3.4] in females; $t$-test, $P$-value $=0.0358$ ).

As regards infections, the percentage of patients with at least one seropositivity detected at baseline, indicative of former viral infection, was significantly higher among women $(68.3 \%)$ than among men $(53.7 \%$; chi-square test, $P$-value $=0.011$ ). As shown by the SYNERGY study, none of these patients developed viral or other infectious diseases during the 12 month follow-up nor developed virus reactivation.

When PASI and BASDAI as indexes of activity of psoriasis and PsA, respectively, were analyzed according to pre- or postmenopausal status in women and compared with men of corresponding age (ie, $<50$ years and $\geq 50$ years), no statistically significant differences between sexes were observed at baseline and at 6 and 12 months of follow-up in either age groups (Table 2).

No differences were observed between males and females in terms of treatment, either in the percentage of treated patients or in the type of medications administered (Table 3).

Finally, adverse events during study were reported in eight men and seven women (chi-square test, $P$-value $>0.05$ ).

\section{Discussion}

Awareness of sex differences in diseases is important among professionals. In order to manage such differences, clinicians should provide for a highly specialized care, which might be particularly useful in psoriasis to provide an equal quality of care for women, who have been reported to suffer from a higher psychosocial distress and a greater impact on quality of life..$^{25,26}$ It has also been reported that peripheral joint involvement and pain are more frequent among female 
A
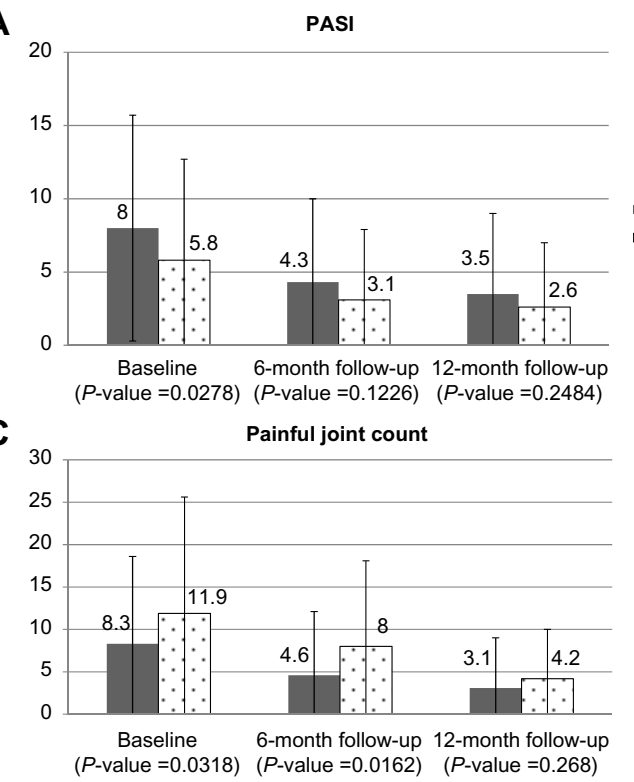

E Global disease activity (patient's assessment)

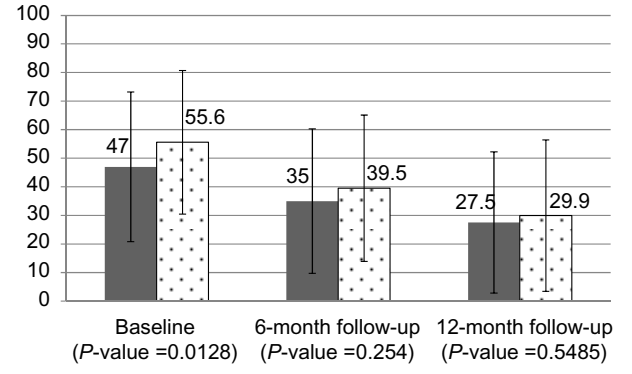

B

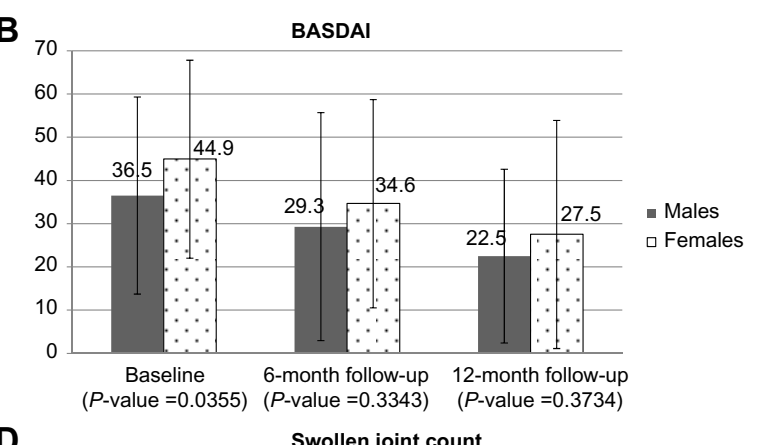

D

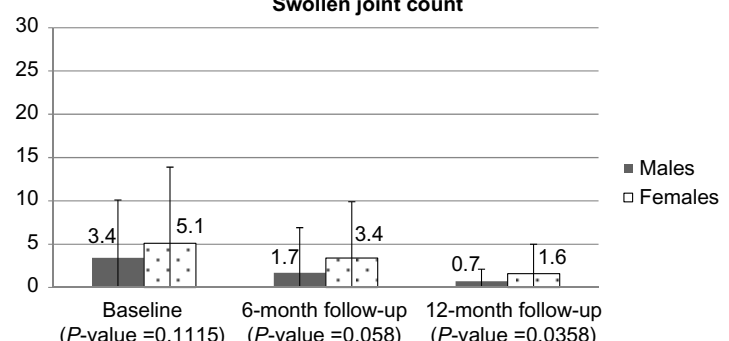

$(P$-value $=0.1115) \quad(P$-value $=0.058) \quad(P$-value $=0.0358)$

F Global disease activity (clinician's assessment)

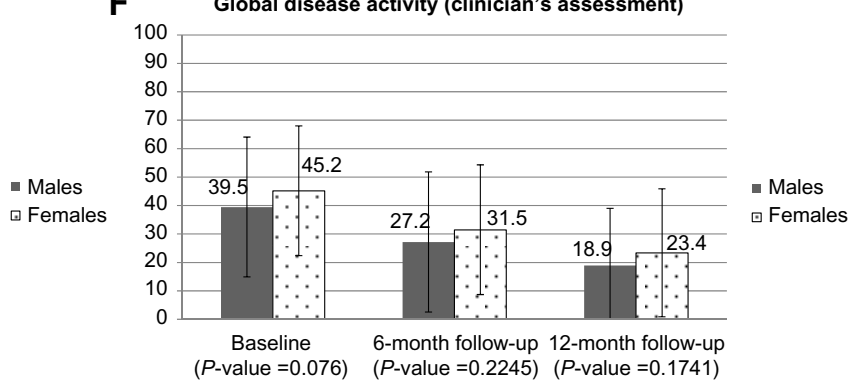

Figure I PASI (A), BASDAI (B), number of painful (C) and swollen joints (D) and indexes of disease activity at each visit (mean \pm standard deviation) (E and F), by sex. Abbreviations: BASDAI, Bath Ankylosing Spondylitis Disease Activity Index; PASI, Psoriasis Area and Severity Index.

psoriatic patients than among male patients. ${ }^{27,28}$ Another recently published article confirmed the greater peripheral involvement in women with PsA (with more frequent polyarthritis) as well as greater physical functional impairment. ${ }^{29} \mathrm{In}$ our analysis, consistently, a significantly greater number of painful joints as well as greater patients' assessed activity of
PsA were observed in female compared to male patients. On the other hand, slightly higher PASI values were observed in men compared to women at baseline. All the aforementioned sex differences disappeared at follow-up visits, but this may be easily explained by the overall progressive improvement of the disease during the study, likely due to participation in the trial

Table 2 PASI and BASDAI in pre- and postmenopausal women compared to age-matched men at each study time point

\begin{tabular}{|c|c|c|c|c|c|c|}
\hline & \multicolumn{3}{|c|}{ PASI mean (SD) } & \multicolumn{3}{|c|}{ BASDAI mean (SD) } \\
\hline & Baseline & 6 months & 12 months & Baseline & 6 months & 12 months \\
\hline & $\mathbf{N}=\mathbf{5 0}$ & $\mathbf{N}=38$ & $N=37$ & $\mathbf{N}=\mathbf{2 3}$ & $N=15$ & $\mathbf{N}=16$ \\
\hline \multirow[t]{2}{*}{ Premenopausal women } & $5.9(7.2)$ & $3.0(4.4)$ & $2.3(4.0)$ & $36.6(22.3)$ & $28.5(25.0)$ & $26.2(29.9)$ \\
\hline & $N=64$ & $\mathrm{~N}=48$ & $\mathrm{~N}=50$ & $\mathbf{N}=40$ & $\mathrm{~N}=\mathbf{2 3}$ & $N=19$ \\
\hline Men aged $<50$ years & $8.2(7.7)$ & $4.9(6.9)$ & 4.I (6.4) & $31.6(22.8)$ & $28.6(27.3)$ & $23.9(23.6)$ \\
\hline \multirow[t]{2}{*}{$P$-value } & 0.1047 & 0.1383 & 0.1147 & 0.3994 & 0.9944 & 0.7992 \\
\hline & $N=53$ & $N=46$ & $\mathrm{~N}=42$ & $N=36$ & $N=26$ & $\mathbf{N}=\mathbf{2}$ I \\
\hline \multirow[t]{2}{*}{ Postmenopausal women } & $5.7(6.6)$ & $3.1(5.1)$ & $2.9(4.7)$ & $50.3(21.9)$ & $38.1(23.3)$ & $28.5(24.1)$ \\
\hline & $N=56$ & $N=45$ & $N=45$ & $\mathbf{N}=34$ & $\mathbf{N}=\mathbf{2 2}$ & $N=16$ \\
\hline Men aged $\geq 50$ years & $7.7(7.8)$ & $3.6(3.8)$ & $2.8(4.1)$ & $42.2(2 \mid .7)$ & $30.0(26.1)$ & $21.0(15.6)$ \\
\hline$P$-value & 0.1487 & 0.5467 & 0.9591 & 0.1279 & 0.2629 & 0.2825 \\
\hline
\end{tabular}

Abbreviations: BASDAI, Bath Ankylosing Spondylitis Disease Activity Index; PASI, Psoriasis Area Severity Index; SD, standard deviation. 
Table 3 Systemic pharmacological treatment for psoriasis and psoriatic arthritis

\begin{tabular}{llllll}
\hline \multirow{2}{*}{$\begin{array}{l}\text { Type of systemic } \\
\text { treatment }\end{array}$} & \multicolumn{2}{l}{ Baseline* } & & \multicolumn{2}{l}{ Follow-up** } \\
\cline { 2 - 3 } \cline { 5 - 6 } & Males & Females & & Males & Females \\
& N (\%) & N (\%) & N (\%) & N (\%) \\
\hline Cyclosporine & $58(47.9)$ & $52(50.0)$ & $52(43.0)$ & $42(40.4)$ \\
Cyclosporine + methotrexate & $17(14.0)$ & $19(18.3)$ & $19(15.7)$ & $15(14.4)$ \\
Cyclosporine + biologics & $16(13.2)$ & $7(6.7)$ & $24(19.8)$ & $21(20.2)$ \\
Cyclosporine + other & $24(19.8)$ & $21(20.2)$ & $16(13.2)$ & $17(16.3)$ \\
Other, not specified & $6(5.0)$ & $5(4.8)$ & $10(8.3)$ & $9(8.7)$
\end{tabular}

Notes: *At baseline, treatment assumed during the last 12 months were recorded; **follow-up refers to the 12th month of study observation period. Other drugs include NSAIDs, corticosteroids, sulfasalazine, retinoids, etc.

Abbreviation: NSAIDS, non-steroidal anti-inflammatory drugs.

per se, sustained pharmacological treatment, and increased use of biologics in combination with CsA during the course of the study, as reported in the SYNERGY paper. ${ }^{18}$

Concerning the pattern of infections, interestingly a higher percentage of women had seropositivity for at least one viral infection. The explanation for this difference is not clear, but might be related to the greater humoral immune responses of females to viral antigens, reported by many authors. ${ }^{30-33}$ The reason for these differences in susceptibility to infections between males and females has been reported to be multifactorial. The primary cause is thought to be due to differences induced by sex hormones and their effects on gene expression as well as the immune system, but may also be due to innate physiological differences between males and females. It has also been suggested that there may be an interaction between sex-specific immune differences and the specific immune response to individual microbes. Menopausal status seems not to affect the severity of disease among women, since stratifying the study population by age $(<50$ years or $\geq 50$ years) seems to flatten differences between sexes. This might be due to the lower sample size in each group.

An important aspect, already pointed out by the SYNERGY study, is that treatment with CsA alone or combined with other immunosuppressant seems not to favor the reactivation of severe viral infections in previously infected patients, with no difference between females and males, even though men have been reported to have an underlying immunosuppressed condition compared to women, due to the immunosuppressive effects of male steroidal sex hormones. ${ }^{34-36}$

Finally, the observation of no difference in the therapeutic approach between sexes is consistent with the findings of the previously conducted MetaGeM analysis of the PSYCHAE study, ${ }^{37}$ confirming that Italian physicians do not adopt different approaches between sexes, even though articular involvement, activity of disease, and psychological distress have been reported to be worse in females.

We are aware that this paper has a limitation to be a post hoc analysis of a study, not specifically aimed at assessing sex differences. Thus, the sample size was not calculated on this specific hypothesis and furthermore, data collection may have missed relevant information. Due to the relatively small sample size, we could not further split the male-female patient populations by CsA monotherapy or combination therapy, and this may be considered another limitation, since the potential interactions with concomitant medications have not been addressed. On the other hand, because of the exploratory aim of these analyses, the significance threshold was set to 0.05 and not corrected. ${ }^{38}$

\section{Conclusion}

The present post hoc sex analysis of the SYNERGY study shows a greater articular involvement and a higher selfassessed disease activity in female patients with PsA as compared to males, which, together with the heavier psychological distress reported in the PSYCHAE study, further suggest that psoriatic women may deserve more attention and probably a slightly different therapeutic approach, including psychological support. Moreover, our analysis shows a higher percentage of viral seropositivities among women. Finally, cyclosporine treatment seems not to induce hepatitis B virus or hepatitis $\mathrm{C}$ virus reactivation in either sex.

\section{Acknowledgments}

The study was supported by an unrestricted educational grant from Novartis Farma SpA, Origgio (VA), Italy. The authors meet criteria for authorship as recommended by the International Committee of Medical Journal Editors (ICMJE) and were fully responsible for all aspects of manuscript development. The authors are grateful to MediData (Modena, Italy) for data collection and statistical analysis and to Sara Rizzoli and Renata Perego for help in writing the manuscript.

\section{Author contributions}

DC and GB contributed to conception, design, and data interpretation. SC contributed to design, data acquisition, and data interpretation. PAG and AM contributed to design and data interpretation. FB and FA contributed to data acquisition and data interpretation. LS contributed to design, data interpretation, and statistical analysis. DV contributed to design and data interpretation. All authors contributed toward data analysis, drafting and revising the paper and agree to be accountable for all aspects of the work. 


\section{Disclosure}

DC is a part-time employee of Novartis Farma SpA, Origgio (VA), Italy and received grants from Allergan and Aventis. SC has received advisory/speaker honoraria and/ or research funding from Abbvie, Merk Sharp and Dome, Novartis, and Pfizer. PAG has received advisory/speaker honoraria and/or research funding from Novartis, Pfizer, MSD, Biotest, AstraZeneca, Gilead, and Astellas. AM has received advisory and speaker honoraria from Novartis. FB has received advisory/speaker honoraria and/or research funding from Abbvie, Janssen, Novartis, Schering-Plough, and Pfizer. FA has received advisory/speaker honoraria and/ or research funding from Abbvie, Janssen, MSD, Novartis, and Pfizer. LS is an employee of MediData srl. DV is an employee of Novartis Farma SpA, Origgio (VA), Italy. GB was an employee of Novartis Farma SpA, Origgio (VA), Italy during study execution and manuscript submission, while at present, he is an employee of UCB Pharma Italy. The authors report no other conflicts of interest in this work.

\section{References}

1. Lesuis N, Befrits R, Nyberg F, van Vollenhoven RF. Gender and the treatment of immune-mediated chronic inflammatory diseases: rheumatoid arthritis, inflammatory bowel disease and psoriasis: an observational study. BMC Medicine. 2012;10:82.

2. Blumenstein I, Herrmann E, Filmann N, et al. Female patients suffering from inflammatory bowel diseases are treated less frequently with immunosuppressive medication and have a higher disease activity. A subgroup analysis of a large, multi-centre, prospective, internet-based study. J Crohn Colitis. 2011;5:203-210.

3. Klein SL, Jedlicka A, Pekosz A. The Xs and Y of immune responses to viral vaccines. Lancet Infect Dis. 2010;10:338-349.

4. Khandaker G, Dierig A, Rashid H, King C, Heron L, Booy R. Systematic review of clinical and epidemiological features of the pandemic influenza A (H1N1) 2009. Influenza Other Resp Viruses. 2011;5:148-156.

5. Sousa H, Silva J, Azevedo L, et al. Epstein-Barr virus in healthy individuals from Portugal. Acta Medica Port. 2011;24:707-712.

6. Puchhammer-Stockl E, Aberle SW, Heinzl H. Association of age and gender with alphaherpesvirus infections of the central nervous system in the immunocompetent host. J Clin Virol. 2012;53:356-359.

7. Torcia MG, Nencioni L, Clemente AM, et al. Sex differences in the response to viral infections: TLR8 and TLR9 ligand stimulation induce higher IL10 production in males. PLoS One. 2012;7(6):e39853. doi:10.1371/journal.pone.0039853.

8. Nadkarni S, McArthur S. Oestrogen and immuno-modulation: new mechanisms that impact on peripheral and central immunity. Curr Opin Pharmacol. 2013;13:576-581.

9. Hernández-Bello R, Nava-Castro K, Muñiz-Hernández S, et al. Beyond the reproductive effect of sex steroids: their role during immunity to helminth parasite infections. Mini Rev Med Chem. 2012;12:1071-1080.

10. Angele MK, Pratschke S, Hubbard WJ, Chaudry IH. Gender differences in sepsis. Cardiovascular and immunological aspects. Virulence. 2014;5:1-8.

11. Mease P. Management of psoriatic arthritis: the therapeutic interface between rheumatology and dermatology. Curr Rheumatol Rep. 2006;8:348-354.
12. Mease PJ. Psoriatic arthritis: update on pathophysiology, assessment and management. Ann Rheum Dis. 2011;70(Suppl 1):i77-i84.

13. Atteno M, Costa L, Matarese A, et al. The use of TNF- $\alpha$ blockers in psoriatic arthritis patients with latent tuberculosis infection. Clin Rheumatol. 2014;33:543-547.

14. Caso F, Cantarini L, Morisco F, et al. Current evidence in the field of the management with TNF- $\alpha$ inhibitors in psoriatic arthritis and concomitant hepatitis C virus infection. Expert Opin Biol Ther. 2015;15:641-650.

15. Costa L, Caso F, Atteno M, et al. Long-term safety of anti-TNF- $\alpha$ in PsA patients with concomitant HCV infection: a retrospective observational multicenter study on 15 patients. Clin Rheumatol. 2014;33: 273-276.

16. Morisco F, Guarino M, La Bella S, et al. Lack of evidence of viral reactivation in $\mathrm{HBs} A g$-negative $\mathrm{HBcAb}$-positive and $\mathrm{HCV}$ patients undergoing immunosuppressive therapy for psoriasis. $B M C$ Gastroenterol. 2014;14:214.

17. Biondo MI, Germano V, Pietrosanti M, et al. Lack of hepatitis B virus reactivation after anti-tumour necrosis factor treatment in potential occult carriers with chronic inflammatory arthropathies. Eur J Intern Med. 2014;25:482-484

18. Colombo D, Chimenti S, Grossi P, et al. Prevalence of past and reactivated viral infections and efficacy of cyclosporine A as monotherapy or in combination in patients with psoriatic arthritis - synergy study: a longitudinal observational study. BioMed Res Int. 2014;Article ID 941767.

19. Icen M, Crowson CS, McEvoy MT, Dann FJ, Gabriel SE, Maradit Kremers H. Trends in incidence of adult-onset psoriasis over three decades: a population-based study. J Am Acad Dermatol. 2009;60: 394-401.

20. Eder L, Thavaneswaran A, Chandran V, Gladman DD. Gender difference in disease expression, radiographic damage and disability among patients with psoriatic arthritis. Ann Rheum Dis. 2013;72:578-582.

21. Klein SL. Sex influences immune responses to viruses, and efficacy of prophylaxis and therapeutic treatments for viral diseases. Bioessays. 2012;34:1050-1059.

22. Taylor W, Gladman D, Helliwell P, et al. Classification criteria for psoriatic arthritis: development of new criteria from a large international study. Arthritis Rheum. 2006;54:2665-2673.

23. Tillett W, Costa L, Jadon D, et al. The ClASsification for Psoriatic ARthritis (CASPAR) criteria - a retrospective feasibility, sensitivity, and specificity study. J Rheumatol. 2012;39:154-156.

24. Amigoni S, Morelli P, Chatenoud L, Parazzini F. Cross-sectional study of determinants of menopausal age and hormone replacement therapy use in Italian women. Climacteric. 2000;3(1):25-32.

25. Finzi A, Colombo D, Caputo A, et al.; for the PSYCHAE Study Group. Psychological distress and coping strategies in patients with psoriasis: the PSYCHAE Study. JEADV. 2007;21:1161-1169.

26. Colombo D, Caputo A, Finzi A, et al; for the PSYCHAE Study Group. Evolution of and risk factors for psychological distress in patients with psoriasis: the PSYCHAE study. Int J Immunopathol Pharmacol. 2010;23:297-306.

27. Lee W, Reveille JD, Davis JC Jr, Learch TJ, Ward MM, Weisman MH. Are there gender differences in severity of ankylosing spondylitis? Results from the PSOAS cohort. Ann Rheum Dis. 2007;66:633-638.

28. Alenius GM, Stenberg B, Stenlund H, Lundblad M, Dahlqvist Rantapaa S. Inflammatory joint manifestations are prevalent in psoriasis - a prevalence study of joint and axial involvement in psoriatic patients and an evaluation of a psoriatic and arthritic questionnaire. J Rheumatol. 2002;29:2577-2582.

29. Queiro R, Tejón P, Coto P, et al. Clinical differences between men and women with psoriatic arthritis: relevance of the analysis of genes and polymorphisms in the major histocompatibility complex region and of the age at onset of psoriasis. Clin Devel Immunol. 2013;2013:482691. doi:10.1155/2013/482691.

30. McClelland EE, Smith JM. Gender specific differences in the immune response to infection. Arc Immunol Ther Exp. 2011;59:203-213.

31. Klein SL, Pekosz A, Passaretti C, Anker M, Olukoya P. Sex, Gender and Influenza. Geneva: World Health Organization; 2010:1-58. 
32. Choi W, Rho B, Lee M. Male predominance of pneumonia and hospitalization in pandemic influenza A (H1N1) 2009 infection. BMC Res Notes. 2011;4:351.

33. Roriz-Cruz M, Rosset I, Montero-Odasso M. Lower mortality from H1N1 influenza in older Argentineans: men more affected. J Am Geriatr Soc. 2010;58:1813-1815.

34. Zandman-Goddard G, Peeva E, Shoenfeld Y. Gender and autoimmunity. Autoimmun Rev. 2007;6:366-372.

35. Gaillard RC, Spinedi E. Sex- and stress-steroids interactions and the immune system: evidence for a neuroendocrine-immunological sexual dimorphism. Domest Anim Endocrinol. 1998;15:345-352.
36. Sakiani S, Olsen NJ, Kovacs WJ. Gonadal steroids and humoral immunity. Nat Rev Endocrinol. 2013;9:56-62.

37. Colombo D, Chimenti S, Giannetti A, Caputo A, Rizzoli S, Bellia G. Therapeutic approaches in psoriasis: a post-hoc analysis of the PSYCHAE study from a gender point of view. Clin Dermatol. 2014;2(2):77-83.

38. Bender R, Lange S. Adjusting multiple testing when and how? J Clin Epidemiol. 2001;54:343-349.

\section{Publish your work in this journal}

Clinical, Cosmetic and Investigational Dermatology is an international, peer-reviewed, open access, online journal that focuses on the latest clinical and experimental research in all aspects of skin disease and cosmetic interventions. All areas of dermatology will be covered; contributions will be welcomed from all clinicians and basic science researchers globally. This journal is indexed on CAS. The manuscript management system is completely online and includes a very quick and fair peer-review system, which is all easy to use. Visit http://www.dovepress.com/testimonials.php to read real quotes from published authors.

Submit your manuscript here: http://www.dovepress.com/clinical-cosmetic-and-investigational-dermatology-journal 